Anne Palmér

Uppsala universitet

DOI: http://dx.doi.org/10.5617/adno.6357

\title{
Kvantiteter i kvalitativt bedömda elevtexter - framtida verktyg för rättvis bedömning?
}

\section{Sammanfattning}

Ett problem i bedömning av skrivprov är bristande samstämmighet mellan bedömare. Att fler än en person bedömer samma skrivprov är ett vanligt sätt att öka samstämmigheten, men denna metod är tidskrävande och kostsam. Ett automatiskt bedömningsverktyg, som ger bedömaren stöd på ett effektivt och förutsägbart sätt, vore därför ett användbart hjälpmedel. I artikeln presenteras en pilotundersökning inför ett framtida arbete med automatisk bedömning av skrivprov, där användbarheten av fyra olika textmått i automatisk bedömning undersöks: textlängd, ordlängd, ordvariationsindex och nominalkvot. Materialet utgörs av två korpusar med benchmarktexter från nationella prov, $\mathrm{Np} 1$ och $\mathrm{Np}$ 3. Varje prov ges i två olika skolämnen, svenska och svenska som andraspråk. I analysen beräknas medel- och medianvärden samt korrelationer för textmåtten och texternas betyg. Resultatet visar att skillnaderna mellan textmåttens värden i de två korpusarna är relativt stora. I Np 3 uppmäts generellt högre värden för de fyra textmåtten än i $\mathrm{Np} 1$. Vidare korrelerar samtliga undersökta textmått med betyg i Np 1, medan de textmått som visar starkast korrelation i Np 1 inte på ett signifikant sätt korrelerar med betyg i $\mathrm{Np} 3$. Dessutom visar analysen att texter från ett av proven, som har samma betyg men har tillkommit inom olika svenskämnen, ligger nära varandra utifrån de objektiva textmåtten. I ett framtida arbete inför automatisk bedömning av skrivprov måste användningen av textmåtten anpassas till det specifika provet. Vidare bör en automatisk bedömning omfatta många fler textegenskaper än de som mäts med de undersökta måtten.

Nyckelord: skrivbedömning, automatisk bedömning, nationella prov, elevtexter, bedömning i svenska och svenska som andraspråk 


\title{
Analyzing Quantity in Qualitatively Assessed Student Texts - a Future Tool for Fair Assessment?
}

\begin{abstract}
In assessing writing one problem is the lack of rater consistency. Letting more than one rater take part in the assessment of the same test is one way of improving rater consistency, but this method is time-consuming and expensive. A tool for automated assessment, giving the human rater support in an effective and predictable way, would therefore be useful. In this article a pilot study is presented, where the usefulness of four automatic text measures in the assessment of writing tests are investigated: text length, word length, word variation and nominal ratio. The data consists of two corpora with benchmark texts from two national tests, $\mathrm{Np} 1$ and $\mathrm{Np} 3$. Each test is given in both Swedish and Swedish as a second language. Mean and median values are calculated, as well as correlations for the text measures and the assessment grades of the texts. The results show important differences between the values of the text measures from the two tests. In $\mathrm{Np} 3$ the values for text measures are generally higher than in Np 1. Further, the four text measures correlate significantly with grades in $N p 1$, but the measures correlating strongest in Np 1 do not show a significant correlation in $\mathrm{Np} 3$. In one of the tests, the texts with the same assessment grade but different school subjects are very similar according to the text measures. The conclusion is that a tool for automated assessment must be adapted to a specific writing test. Furthermore, an automated assessment should include the analysis of a greater amount of text qualities than those having been the focus of this study.
\end{abstract}

Keywords: assessing writing, automated assessment, national tests, student texts, assessment in Swedish and Swedish as a second language

Bedömning av elevers skrivna texter - skrivbedömning - utgör ett eget kunskapsområde inom det större fältet test- och bedömningsforskning. I Norge har detta kunskapsområde studerats inom åtminstone två större, välkända projekt, KAL-projektet (Berge et al., 2005) och NORM-projektet (t.ex. Matre \& Solheim, 2014). Båda projekten har bredd i perspektiv och metoder; i KALprojektet har både textanalys och bedömningsanalys använts medan NORMprojektet har blivit känt för sin användning av interventionsforskning där bedömningskriterier har utvecklats. I Sverige har inga verkligt stora projekt genomförts efter 2000-talets början. Projektet Skrivsyntax från 1970-talet (Hultman \& Westman, 1977) är dock känt som startskottet för en rad svenska 
avhandlingar som har analyserat elevtext och relaterat analysen till bedömning. Kvantitativa metoder för analys av elevtexten har kombinerats med olika kvalitativa angreppssätt (t.ex. Larsson, 1984; Nyström, 2000; Nordenfors, 2011). Tydligt fokus på bedömning av elevtexten finns i svenska avhandlingar som Östlund-Stjärnegårdh (2002) - metodiskt nära traditionen från Hultman \& Westman (1977) - och senare avhandlingar av Skar (2013) och Borgström (2014), som hämtar metoder och perspektiv från psykometri och testteori. Föreliggande artikel tar sin utgångspunkt i välkända kvantitativa metoder för analys av elevtexter. Jämfört med tidigare svenska studier lägger den också till perspektiv och metoder från korpuslingvistik, där automatiska analyser ger möjlighet att överblicka större datamängder och att jämföra delkorpusar med varandra.

Vid bedömning av längre, elevkonstruerade svar som elevtexter - ofta kallade uppsatser - är det långt ifrån självklart att kunna åstadkomma hög interbedömarreliabilitet - samstämmighet om bedömning. Denna tendens är tydlig i internationell forskning om skrivbedömning, där vanliga teman är hur bedömningsanvisningar bör utformas och bedömarträning anordnas för att öka graden av samstämmighet mellan bedömare (t.ex. Harsch \& Martin, 2013; Goodwin, 2016). Berge (2005:106) jämför uppnådd korrelation mellan bedömare i större internationella undersökningar och pekar på behovet att nå en tolkningsgemenskap bland bedömarna, en gemenskap om skrivnormer som kan leda till en pålitlig och rättvis bedömning. I svensk bedömningsforskning diskuterar Ledin \& Borgström (2014:160 ff.) möjligheten att nå denna tolkningsgemenskap, och svensklärarna lyfts fram som den yrkesgrupp som bör ha störst förutsättningar att åstadkomma en samstämmig bedömning av elevtexter. Sambedömning - ett samarbete mellan två eller flera bedömare kring bedömning - förespråkas ofta som ett medel för att nå samstämmighet, exempelvis i de nationella proven i svenska (Skolverket, 2017a:26 f.). I en litteraturgenomgång över internationell forskning visar emellertid Jönsson \& Thornberg (2014:391 ff.) att det inte finns bevis i forskningen för att samstämmigheten ökar med sambedömning, även om lärare som sambedömer själva ofta uppfattar det så. Mot bakgrund av dessa utmaningar i skrivbedömningen framstår det som angeläget att försöka finna nya vägar att förbättra samstämmigheten i skrivbedömningen. I dag, när den tekniska utvecklingen har kommit långt, är det naturligt att fråga sig om vi inte borde utnyttja tekniken och möjligheten till automatisk analys för att om möjligt effektivisera bedömningen och öka samstämmigheten. Denna artikel redovisar en pilotundersökning, där ett första steg tas för att närma den kvalitativa bedömning som görs av människor till automatisk analys av datorer. 


\section{Automatisk bedömning av elevtexter}

För engelska texter finns redan välutvecklade verktyg för automatisk textanalys, till exempel Coh-metrix som är fritt tillgängligt på internet (McNamara et al., 2014) och kommersiellt framtagna bedömningsverktyg som E-rater (Monaghan \& Bridgeman, 2005; Wang \& Davier, 2014). För svenska texter har automatisk bedömning endast tillämpats i ett fåtal fall och då med ett begränsat antal lingvistiska mått för den automatiska analysen (Östling et al., 2013; Kann, 2013). Sedan 2016 finns även Swegram (Näsman, Megyesi \& Palmér, 2017), ett nytt analysverktyg fritt tillgängligt på internet, som har tagits fram för analys av svenska elevtexter. Swegram annoterar och analyserar texter men utför inte någon bedömning. ${ }^{1}$

Det bedömningsverktyg som pilotundersökningen siktar mot är inte tänkt att ersätta bedömning utförd av människor. Tanken är att den mänskliga bedömaren ska kunna få stöd i sin bedömning från ett automatiskt bedömningsverktyg, en form av "second opinion" med nyanserad information om hur elevtexten förhåller sig till ett antal textegenskaper. Styrkan i den automatiskt givna informationen skulle vara effektivitet, förutsägbarhet och objektivitet. Men den automatiska bedömningen skulle definitivt behöva silas genom det mänskliga omdömet - den skulle ses som en del i en sambedömning. Textegenskaper av mer kvalitativ natur, som originalitet i textens tankeinnehåll eller textens kommunikativa röst, kan inte fångas av en dator. Det är också i kombination med en "human rater" som verktyget "E-rater" används vid ETS i USA (Monaghan \& Bridgeman, 2005; Wang \& Davier, 2014).

\section{Syfte}

I artikeln tar jag alltså ett första steg mot ett automatiskt bedömningsverktyg, i en pilotundersökning där det automatiska verktyget är utvecklat för analys men inte bedömning. Genom att applicera den automatiska analysen på elevtexter som tidigare har bedömts kvalitativt och därmed kan anses representera accepterade betygsnivåer, undersöker jag hur texter på dessa betygsnivåer förhåller sig till några kvantitativt mätbara textdrag. Elevtexter som tidigare blivit noggrant, kvalitativt bedömda menar jag kan anses ge uttryck för en existerande tolkningsgemenskap bland de provutvecklare och lärare som arbetar med nationella prov i de två svenskämnena svenska (sve) och svenska som andraspråk (sva). De textnormer som råder inom denna tolkningsgemenskap är dock svårfångade, och jag vill ta reda på om en automatisk, kvantitativ analys av elevtexterna kan göra bilden tydligare. Artikelns syfte är att undersöka på vilka sätt en automatisk, kvantitativt inriktad analys av tidigare kvalitativt bedömda

\footnotetext{
${ }^{1}$ Adress till Swegram: stp.lingfil.uu.se/Swegram
} 
elevlösningar kan ge meningsfull information om texterna, information som kan användas inför utveckling av en framtida, automatisk bedömning.

Mina forskningsfrågor är:

1. Vilka skillnader finns utifrån fyra automatiska textmått - textlängd, ordlängd, ordvariation och nominalkvot - mellan elevtexter från olika prov, olika svenskämnen och olika betygssteg?

2. Hur korrelerar texternas betyg och de fyra textmåtten?

3. Vilka slutsatser kan dras utifrån resultaten i 1 och 2 ovan inför ett framtida arbete med att utveckla ett automatiskt bedömningsverktyg?

\section{Metod och material}

I ett samarbete mellan Gruppen för nationella prov i svenska och svenska som andraspråk och språkteknologer vid Uppsala universitet, har jag varit med om att ta fram ett automatiskt analysverktyg, särskilt anpassat för analys av svenska elevtexter. Verktyget Swegram (Näsman, Megyesi \& Palmér, 2017) utför lingvistisk annotering av svenska texter på såväl lexikal som syntaktisk nivå. Vidare kan verktyget användas för diverse frekvensundersökningar och enklare statistisk analys baserad på den lingvistiska annoteringen. Denna analys effektiviseras av den möjlighet som verktyget ger att filtrera uppladdade texter efter metadata som verktyget läser in, och att jämföra delkorpusar med varandra.

Med hjälp av Swegram har vi också skapat en annoterad elevtextkorpus, Uppsala elevtextkorpus (Megyesi, Näsman \& Palmér, 2016), som i dag omfattar 4000 elevtexter från nationella prov. Korpusen innehåller texter från nationella prov i både grundskolan och gymnasieskolan. ${ }^{2}$ Texterna har samlats in från prov från 1990-talets slut fram till i dag. Varje text är kodad med metadata om exempelvis aktuellt prov, svenskämne, elevens kön samt det betyg texten fått i provet. I undersökningen används data från korpusen, och Swegram används för textanalysen.

Eftersom jag söker efter textnormer som kan anses giltiga för de nationella proven även om de eventuellt inte är explicit uttalade, vill jag arbeta med endast en utvald del ur elevtextkorpusen, nämligen så kallade benchmarktexter. Dessa texter är elevtexter som i tidigare prov har fungerat som exempel på hur provets bedömningsanvisningar ska tolkas. Benchmarktexterna är bedömda och analyserade av expertlärare i de referensgrupper som vid särskilda tillfällen deltar i provkonstruktionen. Minst tre expertlärare har först bedömt varje text enskilt, och därefter har en gemensam bedömning skett i referensgruppen, varefter ett konsensusbetyg har satts. Slutligen har provkonstruktörerna vid Uppsala universitet gjort en kvalitativ analys av varje elevtext, en analys som

\footnotetext{
${ }^{2}$ Gymnasieskolan är den svenska motsvarigheten till norsk ”vidaregående” skola.
} 
ingått i provets bedömningsanvisningar (t.ex. Skolverket, 2017b). Det beskrivna förfarandet innebär alltså att dessa texter kan anses vara goda representanter för den tolkningsgemenskap som provgruppen vid Uppsala universitet representerar.

Texter från två olika prov, Np 1 och $\mathrm{Np} \mathrm{3,} \mathrm{bildar} \mathrm{delkorpusar} \mathrm{med} \mathrm{provens}$ namn. ${ }^{3}$ Två delkorpusar ger möjlighet att jämföra den automatiska analysens giltighet för prov för elever i olika åldrar med olika slags skrivuppgifter och därmed olika utmaningar för bedömningen. Delkorpusen Np 1 utgörs av benchmarktexter från provet i den svenska gymnasieskolans kurser svenska 1 och svenska som andraspråk 1. Delkorpusen Np 3 består av texter från provet i gymnasieskolans kurser svenska 3 och svenska som andraspråk 3. Proven följer läroplanen Lgy11 (Skolverket, 2011). Medan Np 1 ges under gymnasieskolans första år, när eleverna är 16-17 år, ges Np 3 när eleverna är 18-19 år gamla. Materialet omfattar benchmarktexter för Np 1 från 2011 till 2017 och för Np 3 från 2012 till 2017, det vill säga de år då proven har getts i svensk skola. I Np 1 skriver eleven om ett allmänmänskligt ämne, en argumenterande eller utredande text som skulle kunna publiceras på en webb eller i en lokaltidning. Provet Np 3 innebär att eleven skriver om språk eller litteratur, en utredande, sakligt hållen text, som skulle kunna förekomma i en akademisk kommunikationssituation.

De två skolämnena svenska (sve) och svenska som andraspråk (sva) ligger mycket nära varandra, vilket framgår av såväl läroplanen som av de nationella proven. De är också likvärdiga i meritvärdering inför vidare studier. Kravet på elevens kommunikativa förmåga blir därmed lika högt oavsett svenskämne, vilket exempelvis innebär att eleverna ska kunna läsa och skriva samma texter. Det som skiljer i bedömningen av elevens text är snarast toleransen för språkliga brister (t.ex. ordval och grammatik), vilken är större när eleven läser svenska som andraspråk. I proven ges samma skrivuppgift oavsett om eleven studerar ämnet svenska (sve) eller ämnet svenska som andraspråk (sva). Det är därför motiverat att jämföra benchmarktexter från båda svenskämnena för att undersöka i vilken mån texterna håller samma kvalitet - sett utifrån den automatiska analysen. I tabell 1 presenteras undersökningens material.

\footnotetext{
${ }^{3}$ Provet Np 1 heter officiellt Nationellt prov i svenska 1 och svenska som andraspråk 1 . Np 3 heter Nationellt prov i svenska 3 och svenska som andraspråk 3.
} 
Tabell 1. Antal benchmarktexter från två nationella prov 2011-2017, fördelade på svenskämne och betyg

\begin{tabular}{llllllll}
\hline & A & B & C & D & E & F & Totalt \\
\hline Np 1, sve & 28 & 18 & 22 & 18 & 26 & 23 & 135 \\
& & & & & & & \\
Np 1, sva & 3 & 9 & 11 & 6 & 17 & 14 & 60 \\
Np 3, sve & 17 & 15 & 18 & 12 & 19 & 19 & 100 \\
Np 3, sva & 6 & 7 & 10 & 10 & 11 & 9 & 53 \\
\hline
\end{tabular}

Av tabell 1 framgår antalet texter som representerar ett visst provresultat i Np 1 och Np 3, ämnena svenska och svenska som andraspråk. Provresultat uttrycks i betyg, och betygsskalan omfattar fem godkända betyg, där $\mathrm{E}$ är det lägsta och $\mathrm{A}$ det högsta betyget, medan betyget $\mathrm{F}$ är underkänt. Tabellen visar att fördelningen mellan texter som representerar olika betyg är relativt jämn, men en tyngdpunkt finns vid texter som representerar betygen E och F. Denna betygsgräns har av provkonstruktörerna ansetts extra viktig att illustrera i bedömningsanvisningarna, vilket har resulterat i många benchmarktexter. Urvalet är relativt begränsat för ämnet svenska som andraspråk, särskilt för de högre betygsstegen. Därför bör resultaten för dessa betygsnivåer tolkas med försiktighet.

\section{Fyra textmått}

Jag använder inte Swegrams alla möjligheter till analys utan studerar resultatet för fyra textmått. Dessa har valts för att de traditionellt har använts i forskning om skrivutveckling och textkvalitet i bedömningssammanhang.

Textlängd, antal ord per text, är det mest grundläggande måttet. I den automatiska beräkningen räknas graforden, det vill säga en viss följd av bokstäver eller siffror med mellanrum före och efter (jfr Hultman \& Westman, 1977:46). Enligt Hultman \& Westman är textlängd ett mått på elevens produktivitet, "en språkbehärskning som yttrar sig i att man kan använda språket för att lösa den uppgift man har fått” (1977:55). Inom skrivutvecklingsforskning har många forskare visat på starka korrelationer mellan textlängd och ålder (t.ex. Berman \& Verhoeven, 2002; Johansson, 2009:88), och i bedömningsrelaterade studier, där texter av elever i samma ålder med olika goda skrivresultat jämförts, har textlängd framstått som ett vanligt kvalitetskriterium (t.ex. Hultman \& Westman, 1977:54; Larsson, 1984:192). Vagle (2005) som studerar elevtexter från den norska grundskolans examensprov drar slutsatsen att textlängd är mycket relevant som kvalitetskriterium, och detta särskilt vid resonerande, sakinriktat skrivande, när skribenterna är pojkar och man vill skilja mellan högre betyg (s. 376 f.). 
Ordlängd, antalet tecken per ord, "kan sägas fånga upp de två aspekterna variation och specifikation", skriver Hultman \& Westman (1977:76). Att variation delvis kan fångas genom undersökningar av ordlängd beror på att vanliga ord ofta är korta medan de ovanligare och mer specifika orden är längre. Även ordlängd har samband med åldersmässig skrivutveckling (t.ex. Berman \& Verhoeven, 2002). Vidare har det visat sig att ordlängd korrelerar med betyg, och att korrelationens styrka varierar beroende på faktorer som skrivuppgift och textgenre (Hultman \& Westman, 1977:77-78; Vagle, 2005:384-385; Nordenfors, 2011:110-111).

Ordvariation har i internationell forskning studerats med hjälp av ett antal olika mått. Ambitionen är att mäta antalet olika ord i förhållande till det totala antalet ord i en text, men eftersom de vanligaste orden återanvänds oftare ju längre en text är, blir det inte problemfritt att använda kvoten type/token (jfr Johansson, 2009:142 f.; Magnusson \& Johansson Kokkinakis, 2009:47). Därför togs ordvariationsindex, Ovix, fram i projektet Skrivsyntax (Hultman \& Westman, 1977; Hultman, 1994), och måttet har sedan dess använts flitigt främst i Sverige. Ovix beskriver kvoten mellan antalet olika ord och det totala antalet ord i en text, men en särskild logaritm har tagits fram för att göra måttet oberoende av textens längd (Hultman \& Westman, 1977:57 f.). Hultman \& Westman varnar för att Ovix ska uppfattas som ett mått på hur många synonymer av ett och samma ord som används i en text, och de framhåller att måttet snarare mäter synpunktsrikedom: "Troligen är det snarare variationer $\mathrm{i}$ informationsrikedom än i synonymvariation som vårt ordvariationsmått mäter” (1977:60). Ovix beräknas i Swegram enligt formeln: $\log ($ token) / $\log (2-$ (log(types)/log(token)). Måttet har diskuterats kritiskt, till exempel av Nyström (2000:192) som i sin avhandling hävdar att mycket hög ordvariation kan tyda på bristande koherens i en text, varför det antagligen finns ett tak för när Ovix slutar korrelera med textkvalitet.

Nominalkvot är ett mått som grundas på studier av skillnad i ordklassfördelning mellan muntligt och skriftligt språk av olika formalitetsgrader. Måttet användes först av Hultman \& Westman (1977) för att få ett sammanfattande värde i vilken grad stilen i en text kunde beskrivas som nominal - skriftspråklig med koncentration av textens information till nominalfrasen - eller verbal - muntlig med kortare nominalfraser och starkare fokus på information via verb. Nominalkvot anses också mäta textens grad av informationspackning (Melin \& Lange, 2006:48). Nominalkvoten tas fram med hjälp av de ordklasser som hade visat störst skillnader i muntligt respektive skriftligt språk och beräknas av summan av substantiv + prepositioner + particip delat med summan av pronomen + verb + adverb (Hultman \& Westman, 1977:88). Måttet nominalkvot har använts i automatiska analyser av gymnasieelevers texter i ämnet svenska som andraspråk och då visat sig korrelera med ordlängd och ordvariation (Magnusson \& Johansson Kokkinakis, 2009:52-53). Enklare varianter av måttet (summan av substantiv delat med 
summan av verb) har också förekommit i svensk forskning (af Geijerstam, 2006:108).

\section{Genomförande}

Den automatiska analysen i Swegram utgörs av dels lingvistisk annotering (tokenisering, normalisering, ordklasstaggning och syntaktisk analys), dels statistisk analys av längdmått, ordvariation samt nominalkvot. För längdmåtten textlängd och ordlängd ger analysverktyget information om medelvärden per text. För Ovix och nominalkvot beräknas i Swegram värdet för det totala antalet texter i ett urval samt medianen för urvalet. Med utgångspunkt i Swegrams automatiska analys, som ställs samman i Excel, utförs sedan korrelationsberäkningar med signifikanstest för de fyra textmåtten och betyg i statistikprogrammet SPSS. Korrelationsberäkningarna är utförda för Np 1 sve + sva och Np 3 sve + sva men inte för enskilda svenskämnen, eftersom det visade sig att resultaten var relativt lika mellan svenskämnena. I jämförelser mellan undergrupper använder jag medelvärden för textlängd och ordlängd, totalvärden per undergrupp för nominalkvot och medianvärden för Ovix. Tidigare forskning har visat att medianvärdet ska användas för att jämföra Ovix i undergrupper med flera texter (t.ex. Hultman \& Westman, 1977:56; Magnusson \& Johansson Kokkinakis, 2009:53; Nordenfors, 2011:113-115). För korrelationsberäkningarna används Spearman's koefficient, eftersom data inte är approximativt normalfördelade (jfr tabell 1$){ }^{4}$

\section{Resultat}

Resultaten presenteras i tabeller och diagram för ett mått i taget, eftersom fokus i undersökningen är just måttens användbarhet. Resultat för Np 1 sve + sva jämförs med Np 3 sve + sva, och inom ett prov jämförs svenska (sve) med svenska som andraspråk (sva). Därefter presenteras korrelationsanalyser och sist sammanfattas beräkningarnas resultat.

\section{Textlängd}

I tabell 2 presenteras medelvärden för textlängd (antal ord) fördelat på betyg och uppdelat på undergrupper. Standardavvikelse anges inom parentes. Värdena är avrundade till hela tal.

\footnotetext{
${ }^{4}$ Projektadministratör Catrin Isaksson har hjälpt till med resultatbearbetningen i Excel och provgruppens statistiker Tobias Dalberg och Daniel Edin har genomfört beräkningar i SPSS.
} 
Tabell 2. Textlängd och betyg, medelvärden för Np 1, sve och sva, samt Np 3, sve och sva

\begin{tabular}{lllllll}
\hline & A & B & C & D & E & F \\
\hline Np 1, sve+sva & $594(69)$ & $523(105)$ & $464(110)$ & $446(82)$ & $377(79)$ & $368(94)$ \\
Np 1, sve & $594(72)$ & $562(101)$ & $442(107)$ & $441(78)$ & $359(75)$ & $360(111)$ \\
Np 1, sva & $591(52)$ & $446(66)$ & $509(107)$ & $462(102)$ & $406(79)$ & $381(57)$ \\
Np 3, sve+sva & $734(97)$ & $702(96)$ & $735(178)$ & $743(106)$ & $704(92)$ & $711(120)$ \\
Np 3, sve & $734(98)$ & $728(100)$ & $735(213)$ & $738(86)$ & $705(99)$ & $731(94)$ \\
Np 3, sva & $698(97)$ & $646(60)$ & $694(83)$ & $750(131)$ & $725(85)$ & $687(161)$ \\
\hline
\end{tabular}

Den genomsnittliga textlängden i Np 1 varierar mellan 359 och 594 ord per text. I Np 3 är texterna mellan 646 och 750 ord långa i genomsnitt. Medelvärdena är alltså genomgående högre i kurs 3-provet än i kurs 1-provet. Skillnaden mellan lägsta och högsta medelvärdet är mindre i Np 3 (104) än i Np 1 (235), vilket tyder på att textlängden är mer homogen i Np 3 över betygen. Inom betygsgrupperna är standardavvikelsen ofta strax under eller nära 100 ord, med undantag för Np 3 sve, betyg C, där den individuella variationen är högre.

Diagram över resultatet per prov kan ge en bild av sambandet mellan textlängd och betyg. Figur 1 visar hur den genomsnittliga textlängden i antal ord (y-axeln) fördelar sig beroende på betyg (x-axeln) och svenskämne i Np 1.

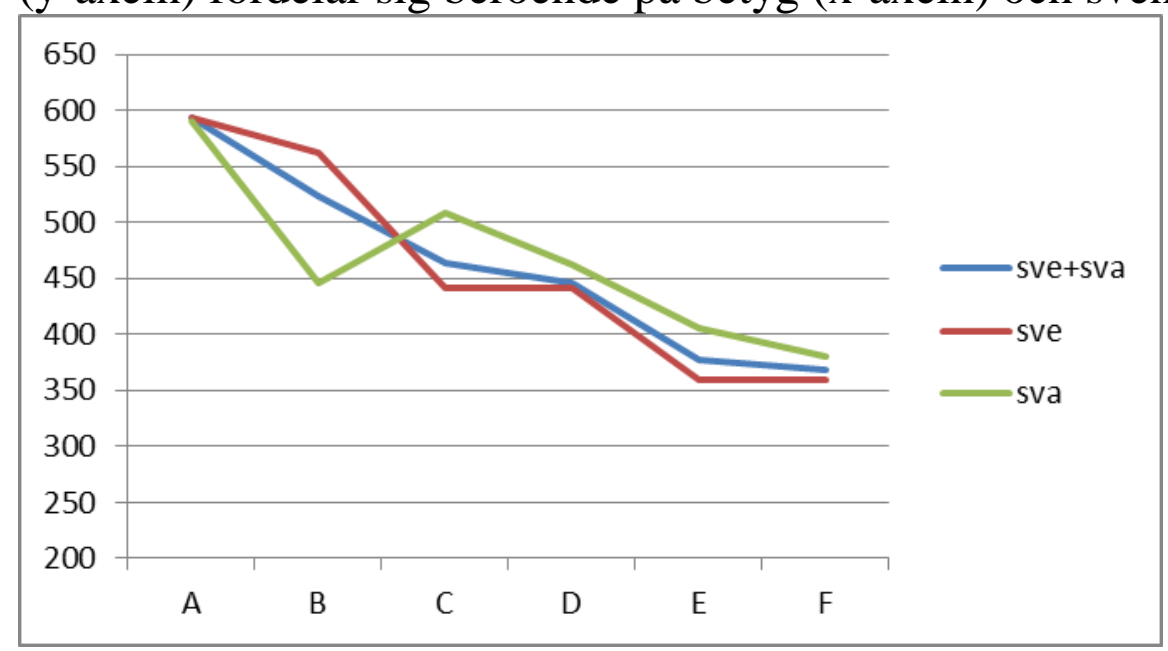

Figur 1. Textlängd, medelvärden per betyg, Np 1, sve och sva

Textlängden för Np 1 sve och Np 1 sva följs åt med undantag för betyg B där medelvärdet för Np 1 sva ligger lägre än Np 1 sve. I ämnet svenska som andraspråk är texterna något längre än i ämnet svenska för betygsstegen $\mathrm{F}$ till $\mathrm{C}$, men skillnaden är liten. Kurvans stigning talar för ett starkt samband mellan medelvärdet för antal ord och betyg.

Ett motsvarande diagram i figur 2 för Np 3 visar på ett helt annat mönster: 


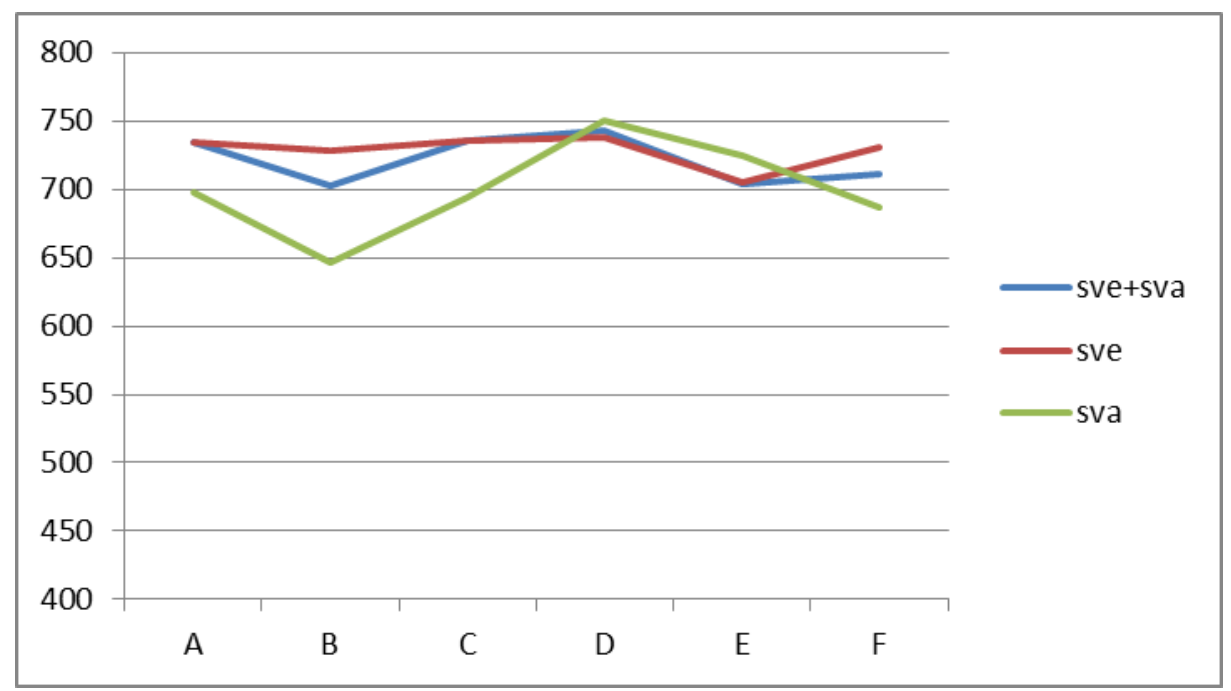

Figur 2. Textlängd, medelvärden per betyg, Np 3 sve och sva

Jämfört med Np 1 är det mest anmärkningsvärda att den genomsnittliga textlängden i Np 3 inte ökar med högre betyg. I Np 3 sva är medeltextlängden från betyg $\mathrm{D}$ något lägre än texter på motsvarande betygssteg i $\mathrm{Np} 3$ sve. Resultaten för textgrupperna med de högsta betygen i Np 3 sva bör tolkas med försiktighet på grund av det begränsade textunderlaget (se tabell 1).

\section{Ordlängd}

Den genomsnittliga ordlängden (antal tecken per ord) i materialet presenteras i tabell 3. Standardavvikelse anges inom parentes.

Tabell 3. Ordlängd, medelvärden per betyg, Np 1, sve och sva, samt Np 3, sve och sva

\begin{tabular}{lllllll}
\hline & A & B & C & D & E & F \\
\hline Np 1, sve+sva & $4,68(0,28)$ & $4,61(0,23)$ & $4,51(0,26)$ & $4,37(0,18)$ & $4,41(0,26)$ & $4,45(0,25)$ \\
Np 1, sve & $4,67(0,27)$ & $4,59(0,25)$ & $4,54(0,28)$ & $4,33(0,16)$ & $4,37(0,21)$ & $4,41(0,30)$ \\
Np 1, sva & $4,74(0,43)$ & $4,64(0,18)$ & $4,46(0,21)$ & $4,46(0,21)$ & $4,46(0,31)$ & $4,45(0,17)$ \\
Np 3, sve+sva & $5,36(0,23)$ & $5,16(0,27)$ & $5,14(0,26)$ & $5,12(0,23)$ & $5,01(0,29)$ & $5,07(0,27)$ \\
Np 3, sve & $5,36(0,24)$ & $5,11(0,25)$ & $5,07(0,20)$ & $5,06(0,20)$ & $4,94(0,26)$ & $5,05(0,28)$ \\
Np 3, sva & $5,35(0,19)$ & $5,28(0,29)$ & $5,27(0,32)$ & $5,19(0,24)$ & $5,15(0,31)$ & $5,12(0,26)$ \\
\hline
\end{tabular}

Ordmedellängden inom provet Np 1 varierar mellan 4,33 och 4,74 tecken per ord. Inom Np 3 går ordmedellängden från som lägst 4,94 till som högst 5,36 tecken per ord. Ordmedellängden i Np 3 är alltså markant högre än i Np 1. Den individuella variationen inom betygsgrupperna håller sig oftast mellan 0,1 och 0,3. De följande diagrammen får illustrera ordmedellängden per prov, svenskämne och betyg. Y-axeln visar medelvärdet av antal tecken per ord och Xaxeln betyg. 


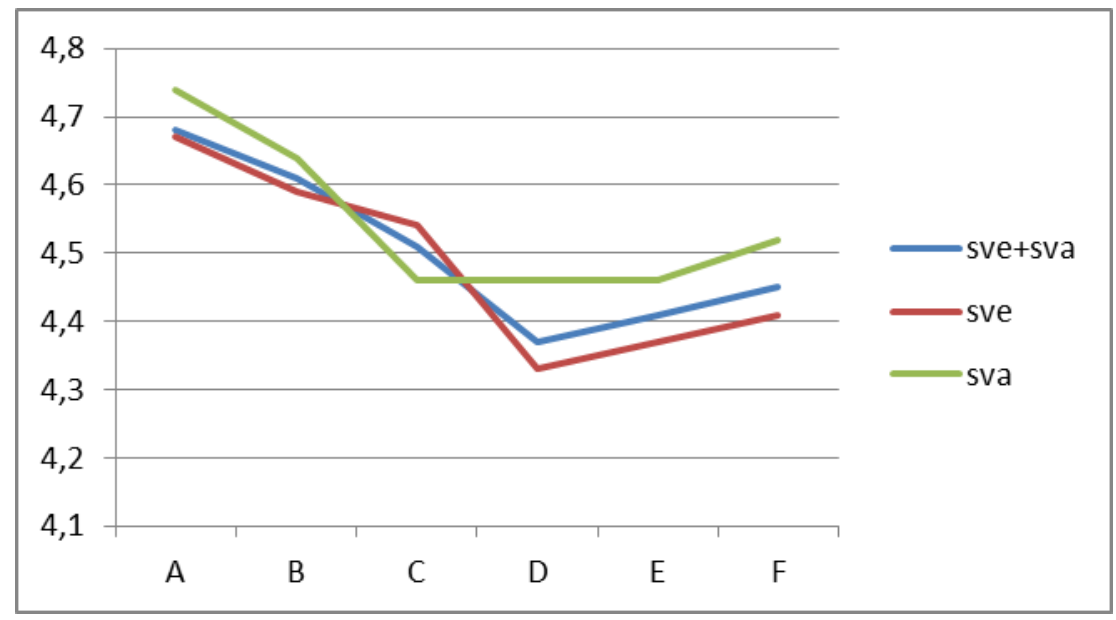

Figur 3. Ordlängd, medelvärden per betyg, Np 1, sve och sva

Av figur 3 framgår att ordmedellängden per betyg i texter från Np 1 sva oftast ligger något högre än $\mathrm{i}$ texter från $\mathrm{Np} 1$ sve. För betyget $\mathrm{F}$ till $\mathrm{D}$, de lägre betygsstegen, är sambandet ordlängd-betyg försumbart eller negativt i alla undergrupper, men från betyget $\mathrm{D}$ för svenska eller $\mathrm{C}$ för $\mathrm{Np} 1$ sva stiger ordmedellängden med betygen. Ordmedellängden verkar alltså ha betydelse för att skilja mellan högre betyg, men inte för att skilja mellan lägre betyg. Ordmedellängden i Np 3 presenteras i figur 4.

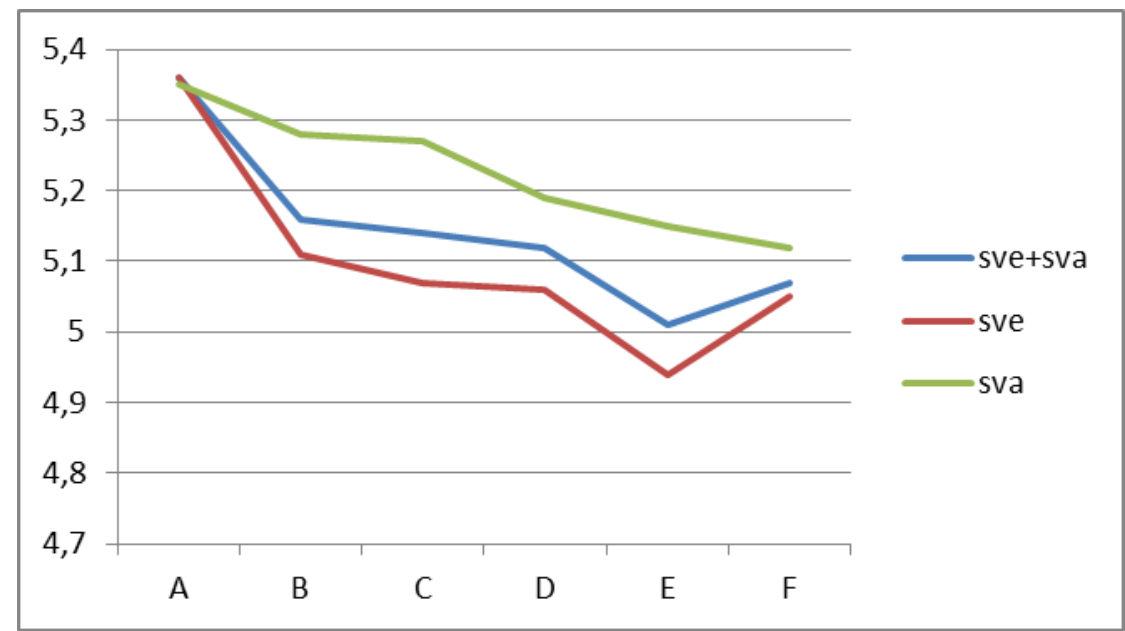

Figur 4. Ordlängd, medelvärden per betyg, Np 3, sve och sva

F-texterna i Np 3 sve har något högre ordmedellängd än E- och D-texterna, men bortsett från det stiger ordlängden med högre betyg. Np 3 sva har högre värden än Np 3 sve.

\section{Ordvariation}

Tabell 4 presenterar medianvärden för Ovix och betyg. Standardavvikelser anges inom parentes. 
Tabell 4. Ovix och betyg, medianvärden för Np 1, sve och sva, samt Np 3, sve och sva

\begin{tabular}{lllllll}
\hline & A & B & C & D & E & F \\
\hline Np 1, sve+sva & $56,4(6,8)$ & $56,44(4,5)$ & $51,88(4,7)$ & $48,3(7,1)$ & $48,6(5,5)$ & $47,6(6,8)$ \\
Np 1, sve & $56,7(7)$ & $55,3(4,9)$ & $51,76(5,3)$ & $48,2(6,8)$ & $48,9(5,3)$ & $48,3(7,1)$ \\
Np 1, sva & $55,8(3,3)$ & $56,4(3,9)$ & $51,9(3,2)$ & $51,9(8,8)$ & $48,6(5,8)$ & $45,8(6,3)$ \\
Np 3, sve+sva & $59,9(6,5)$ & $57,5(5)$ & $58(6,2)$ & $58,4(6,5)$ & $56,4(4,6)$ & $57,2(6,7)$ \\
Np 3, sve & $62,5(6,5)$ & $57,5(5,3)$ & $58,9(6,2)$ & $61,4(6,4)$ & $56,4(4,2)$ & $60,8(6,8)$ \\
Np 3, sva & $58,8(4,5)$ & $58,3(4,6)$ & $56,9(6,1)$ & $56,1(7)$ & $56,5(5,4)$ & $53,4(5,7)$ \\
\hline
\end{tabular}

Ovix-medianen i materialet från $\mathrm{Np} 1$ varierar mellan 45 och 56, medan medianen i Np 3 varierar mellan 53 och 62, det vill säga en något mindre variation än för Np 1. Den individuella variationen ligger mellan 3 och 7 steg, i ett enda fall 8 steg. Figur 5 och 6 illustrerar skillnader mellan svenskämnena och sambandet mellan Ovix-medianerna och betyg, uppdelat på prov.

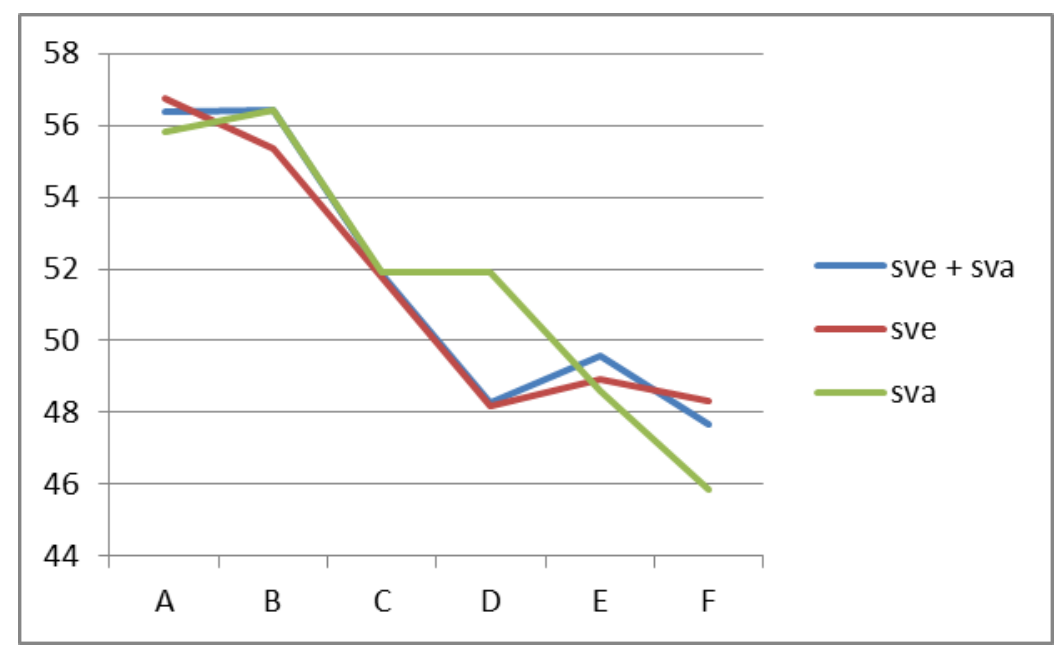

Figur 5. Ovix, median per betyg, Np 1, sve och sva

Ordvariationen för svenska i Np 1 sve + sva är utifrån medianvärden stigande med högre betyg från betyg $\mathrm{D}$ till $\mathrm{B}$. Np 1 sva är stigande från $\mathrm{F}$ till $\mathrm{D}$ och följer $\mathrm{Np} 1$ sve från betyg $\mathrm{C}$ och uppåt. Figur 6 visar att Np 3 har ett helt annat mönster. 


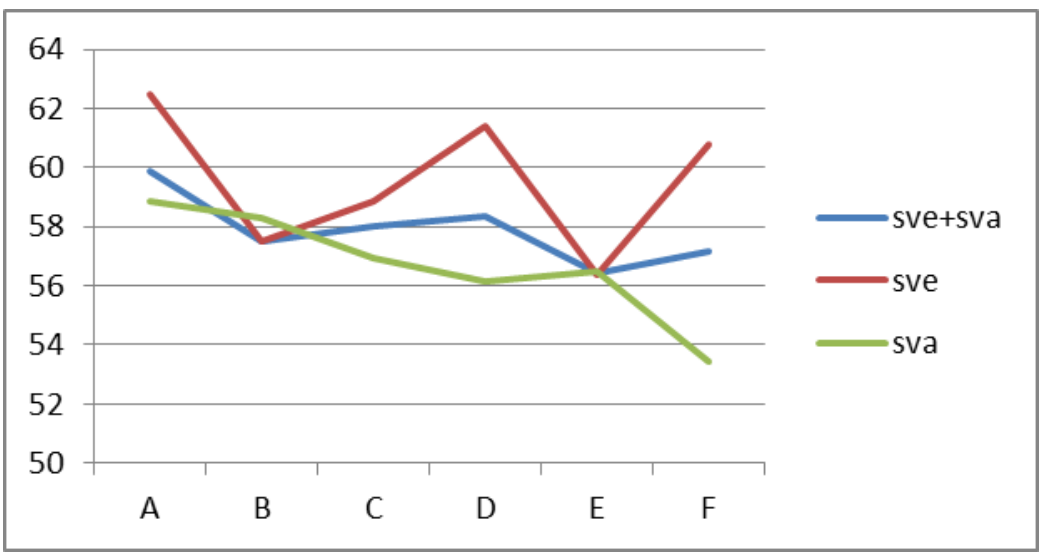

Figur 6. Ovix, median per betyg, Np 3, sve och sva

Kurvan för Np 3 sve tyder på en avsaknad av samband mellan Ovix och betyg i denna textgrupp. I Np 3 sva är Ovix-medianen visserligen stigande med högre betyg, men underlaget för denna textgrupp är begränsat. Ovix-medianen i Np 3 sve ligger ofta över medianen i Np 3 sva, bortsett från betygen E och B.

\section{Nominalkvot}

Nominalkvoten, det sammanfattande värdet för texternas grad av nominalitet, är det sista språkmåttet som används. Tabell 5 visar totalvärdet för nominalkvot per betyg i båda proven, uppdelat på undergrupper. Standardavvikelse anges inom parentes.

Tabell 5. Nominalkvot och betyg, totalvärden för Np 1, sve och sva, samt Np 3, sve och sva

\begin{tabular}{lllllll}
\hline & A & B & C & D & E & F \\
\hline Np 1, sve+sva & $0,69(0,20)$ & $0,71(0,16)$ & $0,65(0,14)$ & $0,56(0,12)$ & $0,59(0,21)$ & $0,64(0,22)$ \\
Np 1, sve & $0,69(0,20)$ & $0,69(0,18)$ & $0,64(0,16)$ & $0,54(0,09)$ & $0,55(0,11)$ & $0,63(0,16)$ \\
Np 1, sva & $0,71(0,23)$ & $0,76(0,13)$ & $0,66(0,10)$ & $0,62(0,17)$ & $0,65(0,30)$ & $0,66(0,26)$ \\
Np 3, sve+sva & $1,32(0,22)$ & $1,14(0,30)$ & $1,12(0,27)$ & $1,07(0,31)$ & $0,98(0,26)$ & $1,06(0,28)$ \\
Np 3, sve & $1,31(0,22)$ & $1,17(0,33)$ & $1,05(0,23)$ & $0,98(0,24)$ & $0,93(0,26)$ & $1,01(0,22)$ \\
Np 3, sva & $1,36(0,26)$ & $1,09(0,21)$ & $1,27(0,26)$ & $1,18(0,35)$ & $1,13(0,25)$ & $1,12(0,35)$ \\
\hline
\end{tabular}

Nominalkvoten för Np 1 ligger generellt lägre (variation mellan 0,54 och 0,76) än motsvarande värden för $\mathrm{Np} 3$ (variation mellan 0,93 och 1,36). Standardavvikelsen rör sig från 0,1 till som högst 0,35. Figur 7 illustrerar värdena för nominalkvot i Np 1. 


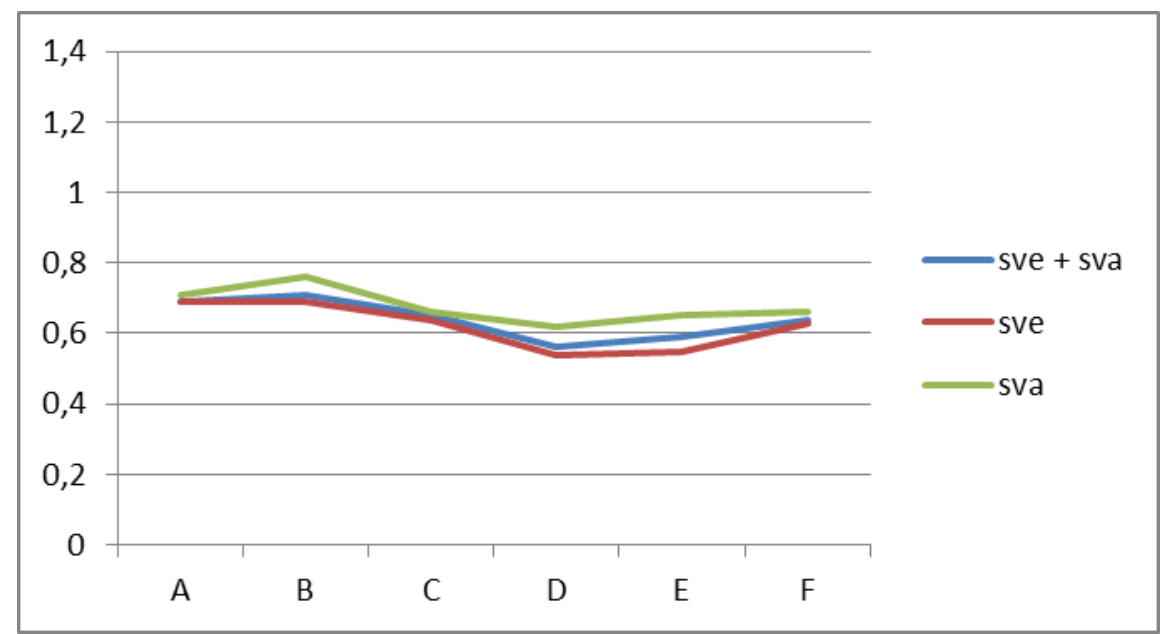

Figur 7. Nominalkvot, totalvärden per betyg, Np 1, sve och sva

Nominalkvoten i betygsgrupperna sjunker något från betyget $\mathrm{F}$ till $\mathrm{E}$ och $\mathrm{D}$ och stiger därefter mycket svagt i både Np 1 sve och Np 1 sva. Svenskämnena följs åt vad gäller nominalkvot relaterat till betyg i Np 1, och Np 1 sva ligger bara någon tiondel över Np 1 sve.

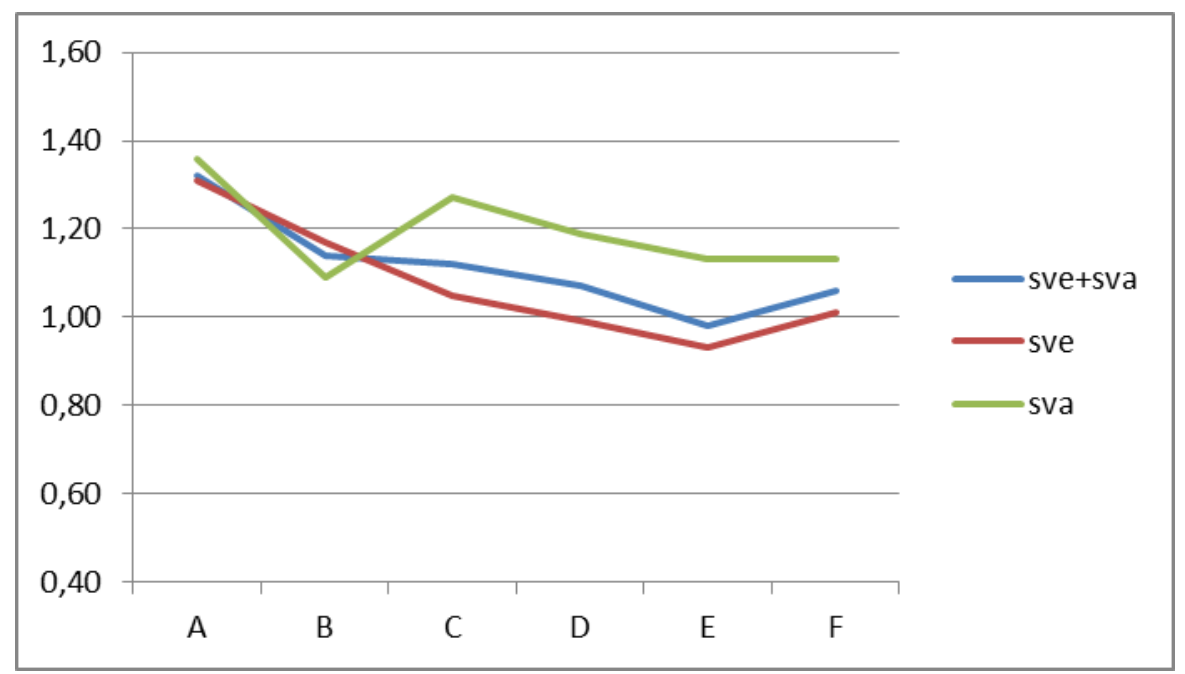

Figur 8. Nominalkvot, totalvärden per betyg, Np 3, sve och sva

Av figur 8 framgår att totalvärdena för nominalkvoten i Np 3 sva ligger högre än i Np 3 sve, bortsett från dippen vid betyg B som inte bör tillmätas stor betydelse på grund av det begränsade underlaget. Ett visst samband nominalkvot-betyg går också att utläsa av diagrammet.

\section{Korrelationer}

I detta avsnitt presenteras uppmätta korrelationer enligt Spearman. Tabell 6 behandlar Np 1 sve + sva och tabell $7 \mathrm{~Np} 3$ sve + sva. Det signifikansmått som avses är $\mathrm{p}=.01$. 
Tabell 6. Korrelationer betyg-språkmått samt signifikans, Np 1 sve och sva

\begin{tabular}{lll}
\hline & Spearman & Signifikans \\
\hline Betyg och antal ord & .65 & $\mathrm{Ja}$ \\
Betyg och Ovix & .44 & $\mathrm{Ja}$ \\
Betyg och ordlängd & .38 & $\mathrm{Ja}$ \\
Betyg och nominalkvot & .21 & $\mathrm{Ja}$ \\
\hline
\end{tabular}

Tabell 7. Korrelationer betyg-språkmått samt signifikans, Np 3 sve och sva

\begin{tabular}{lll}
\hline & Spearman & Signifikans \\
\hline Betyg och ordlängd & .29 & Ja \\
Betyg och nominalkvot & .28 & Ja \\
Betyg och Ovix & .13 & Nej \\
Betyg och antal ord & -.01 & Nej \\
\hline
\end{tabular}

Korrelationsanalysen visar att samtliga undersökta språkmått har statistiskt signifikanta korrelationer i Np 1 sve + sva, medan endast ordlängd och nominalkvot korrelerar på ett signifikant sätt i Np 3 sve + sva. De språkmått som i Np 1 har starkast korrelationer med betyg - textlängd och Ovix - korrelerar i Np 3 inte på ett signifikant sätt med betyg.

\section{Sammanfattning av beräkningarna}

Analysen av textlängd har visat att texter i Np 3 är genomsnittligt längre och mer homogena än Np 1-texterna. Vidare framgår i Np 1 en stark korrelation mellan medelvärdena av textlängd och betyg $(r=.65 ; \mathrm{p}=0.1)$, men i Np 3 är korrelationen negativ och icke-signifikant $(r=.-01)$. Skillnaderna mellan svenskämnena är små i Np 1. I Np 3 sva framgår en tendens till genomsnittligt något kortare texter än i $\mathrm{Np} 3$ sve.

Ordmedellängden är genomgående och markant högre för Np 3 än Np 1, och korrelationen ordmedellängd-betyg är måttlig i de båda proven $(\mathrm{Np} 1: \mathrm{r}=.38$; Np 3: $r=.29$ ). Ordmedellängd verkar i Np 1 ha betydelse framför allt för att skilja texter på mittennivå från högre betyg, medan måttet i Np 3 är svagt stigande genom alla betygssteg för sva, och från E och uppåt i ämnet svenska. Det finns en tendens till högre ordmedellängd i sva än i sve, och samma tendens är tydlig i Np 3.

Analysen med hjälp av måttet Ovix visar att även ordvariationen generellt är högre i Np 3 än i Np 1 . I Np 1 visar diagram och korrelationsmått $(r=.44)$ att det finns ett relativt starkt samband mellan Ovix och betyg. Ett motsvarande samband finns däremot inte i Np $3(r=.13)$. Medan Ovix är ungefär lika i Np 1 sve och Np 1 sva finns en tendens, om än inte särskilt tydlig, i Np 3 till att ordvariationen är högre i sve än i sva. 
Slutligen framgår det i analysen av nominalkvot att också detta mått generellt har högre värden i Np 3 än i Np 1. Sambandet nominalkvot-betyg är relativt svagt i båda proven, men starkare i Np $3(\mathrm{r}=.28)$ än i Np $1(\mathrm{r}=.21)$. Medan nominalkvoten i Np 1 är ungefär lika mellan svenskämnena, ligger den för Np 3 sva något högre än för $\mathrm{Np} 3$ sve.

\section{Slutsatser och diskussion}

I denna artikel har jag undersökt vilken information fyra kvantitativa, automatiskt mätbara språkmått ger om kvalitativt bedömda benchmarktexter från två olika nationella prov i svenska och svenska som andraspråk. Genom att jämföra den kvantitativa, automatiska analysen med den kvalitativa analys av texterna som är gjord av mänskliga bedömare har syftet varit att ta reda på i vilken mån de fyra språkmåtten är användbara inslag i ett framtida, automatiskt bedömningsverktyg, som skulle kunna utgöra ett stöd för den mänskliga bedömaren. Måttet textlängd antas visa elevens produktivitet medan måttet Ovix ses som ett mått på textens grad av ordvariation och synpunktsrikedom. Ordförrådets grad av variation och precision mäts via måttet ordlängd, och måttet nominalkvot antas visa grad av skriftspråklig (nominal) stil i elevtexten. Nedan diskuteras resultatet utifrån de tre forskningsfrågorna, varefter en konklusion presenteras.

\section{Egenskaper i elevtexter från två skrivprov, två skolämnen och två uppgiftstyper}

Den första forskningsfrågan inriktas på att urskilja skillnader utifrån de fyra textmåtten mellan elevtexter från olika prov, olika svenskämnen och olika betygssteg. Analysen visar att elevtexter från de två proven utgör textgrupper med delvis gemensamma, delvis olika egenskaper. För det första ger textmåtten högre värden för texter från $\mathrm{Np} 3$ än texter från $\mathrm{Np}$ 1, det vill säga Np 3-texterna är genomsnittligt längre, har genomsnittligt längre ord, högre ordvariation och högre nominalkvot. Detta resultat tyder på att Np 3-texterna är mer innehållsrika och språkligt mer avancerade än Np 1-texterna.

Utifrån tidigare forskning om skrivutveckling (t.ex. Berman \& Verhoeven, 2002; Johansson, 2009) är de högre värdena i Np 3 ett förväntat resultat med tanke på att det skiljer två gymnasieår mellan elevgrupperna. De två proven innehåller också två olika uppgiftstyper, i Np 3 att skriva en utredande text i en akademisk kommunikationssituation, och i Np 1 att argumentera eller utreda en allmänmänsklig fråga för en webbsida eller lokaltidning. Enligt tidigare forskning har också skrivuppgiften och textens genre betydelse för vilka kvantitativa egenskaper texten får (jfr Vagle, 2005; Nordenfors, 2011:110-111). Därför är det förväntat att skrivuppgiften i Np 3 leder till en mer nominal och 
skriftspråklig stil i elevtexterna, än skrivuppgiften i Np 1, som verkar främja ett mindre formellt skriftspråk.

Dessutom visar analysen att texter från samma prov, som har samma betyg men har tillkommit inom olika svenskämnen, kan ligga nära varandra utifrån de objektiva textmåtten. Detta gäller för $\mathrm{Np} 1$, där värdena för alla de fyra textmåtten i Np 1 sva ligger mycket nära värdena för Np 1 sve. En elevtext som får betyget $\mathrm{C}$ på en text skriven i kursen svenska som andraspråk 1 har alltså många språkliga egenskaper gemensamt med en text som får samma betyg men är skriven i kursen svenska 1 . I tidigare forskning finns vad jag vet inga exempel på motsvarande förhållande. I Magnusson \& Johansson Kokkinakis (2009) jämförs texter från ett tidigare nationellt prov i svenska som andraspråk med texter från samma prov i ämnet svenska, och här uppvisar gruppen från svenska som andraspråk lägre värden än gruppen från ämnet svenska utifrån textmåtten ordlängd, Ovix och nominalkvot. De två grupperna i den undersökningen var dock inte jämförbara betygsmässigt, vilket kan förklara resultatet.

I Np 3 finns större skillnader. Np 3 sva-texterna är något kortare (främst högre betyg), har längre ord (alla betyg utom $\mathrm{A}$ ), lägre ordvariation och högre nominalkvot (främst lägre betyg och mellanbetyg) än texterna i Np 3 sve. Min tolkning av dessa skillnader är att texterna i Np 3 sva är något mindre innehållsrika, baserat på måtten textlängd och Ovix, och har en mer skriftspråklig och formell stil, baserat på ordlängd och nominalkvot, än Np 3 sve. Att texterna från svenska som andraspråk därmed ser ut att innehålla ett mer avancerat skriftspråk kan tyckas förvånande. En uppgift för fortsatt forskning är att ta reda på om detta resultat har ett samband med elevernas källanvändning, där elever i svenska som andraspråk eventuellt använder sig mer av citat än elever i svenska, vilket skulle kunna höja värdena för ordlängd och nominalkvot.

Den genomgående höga nominalkvoten i Np 3 kan förvåna, utifrån uppfattningen att en nominal stil kan vara svårläst och tung. Den uppmätta nominalkvoten i Np 3-korpusen är exempelvis betydligt högre än elevtexter och ibland högre än vuxentexter i Hultman \& Westman (1977:88). Vid en jämförelse måste dock textens genre vägas in. Skrivuppgiften i centralprovet från 1970-talet byggde på läsning men eleverna skrev en debattartikel, vilket leder till ett mer självständigt språk och ett visst bruk av källhänvisningar. I Np 3-texterna, som ska vara akademiska utredande texter, finns en stor mängd källhänvisningar som ofta leder till långa nominalfraser. Sannolikt påverkas alltså nominalkvoten av textgenren och elevernas sätt att formulera källhänvisningar. Något att gå vidare med är att mäta nominalkvot i Np 3-texterna när elevtexten rensats från sådana källhänvisningar.

\section{Samband mellan textmått och betyg}

Studiens andra forskningsfråga behandlar korrelationen mellan textmåtten och de kvalitativt satta betyg som benchmarktexterna representerar. Den underliggande premissen för undersökningen är att tydliga samband mellan 
textmått och betyg skulle kunna visa att det aktuella måttet har betydelse i den kvalitativa bedömningen. Även om måttet inte explicit har använts när texterna bedömts kvalitativt skulle det - om korrelation med betyg föreligger - kunna vara användbart $\mathrm{i}$ en framtida automatisk bedömning. Analysen visar att textmåttens samband med betyg ser olika ut i de båda proven. I Np 1 är korrelationen textlängd-betyg stark. Korrelationen är tydlig om än inte stark även för ordvariation och ordlängd, medan korrelationen nominalkvot-betyg är signifikant men svag. Mönstret i Np 3 är annorlunda med en signifikant korrelation endast för ordlängd-betyg och nominalkvot-betyg. Jämfört med tidigare undersökningar är Np 1-mönstret det förväntade. I stora drag stämmer det överens med exempelvis Hultmans \& Westmans (1977) undersökning av elevtexter från 1970-talet och även med undersökningen av Östling et al. (2013) där analysen gäller elevtexter från ett tidigare nationellt prov i kursen Svenska B som gavs enligt läroplanen Lpf94 (Utbildningsdepartementet, 1994).

Att korrelationerna i Np 3 skiljer sig från Np 1 hänger sannolikt ihop med skrivuppgiften i Np 3. Medan skrivprov för gymnasieskolan vanligen innebär att eleven ska utveckla ett självständigt resonemang kring en fråga, har $\mathrm{Np} \mathrm{3-}$ uppgiften i stället fokus på sakligt skrivande utifrån läsning. Eleven ska utreda en given fråga med hjälp av ett antal källor, och den bearbetning av källorna som eleven utför har stor betydelse för resultatet. Stora delar av elevtexten består därmed av referat, och det är först i den avslutande delen av texten som eleven formulerar sig självständigt. Den automatiska analysen av Np 3-korpusen visar att textlängd och ordvariation inte är kvaliteter som skiljer texter med högre betyg från dem med lägre betyg, även om en viss textlängd är genomgående i provets benchmarktexter. Ordlängd och nominalkvot tycks dock ha betydelse för skillnaden mellan betygsnivåer i bedömningen. Det är alltså inte faktorer som elevens produktivitet och textens synpunktsrikedom som avgör skillnaden mellan betygen i Np 3. I stället framstår bland annat precision och variation i ordförrådet och en passande, nominal stil som viktiga kriterier för bedömningen.

En mer detaljerad analys av sambanden mellan språkmåttens värden och betyg visar också att styrkan i dessa samband kan variera över betygsskalan. I både Np 1 och Np 3 i ämnet svenska stiger genomsnittsvärdena för ordlängd mer vid de högre betygen än vid de lägre (figur 3, figur 4). Precision och variation i ordförrådet verkar alltså vara en tydligt betygsskiljande faktor för texter i betygsskalans övre skikt, och detta gäller båda proven. Ordvariationen visar liknande tendenser i Np 1 svenska, det vill säga ett relativt tydligt samband från betyget $\mathrm{D}$ och uppåt men inte för de lägre betygen (figur 5). Nominalkvotbetyg visar i Np 1 en liknande tendens som ordlängd-betyg, det vill säga obefintligt samband för de lägre betygen, men ett visst samband från betyget $\mathrm{D}$ och uppåt i båda ämnena. I Np 3 är sambandet positivt från betyget $\mathrm{E}$ och uppåt. Steget från det lägsta betyget $\mathrm{F}$ till betyget $\mathrm{E}$ innebär i flera fall i båda proven sjunkande värden (t.ex. för ordlängd: figur 3, figur 4; ordvariation: figur 6; 
nominalkvot: figur 7, figur 8). Benchmarktexter med betyget E, som är ett "godkänt" betyg, har alltså sällan ett mer avancerat språk än texter som bedömts med det lägsta betyget F, som inte anses vara godkänt. Detta tyder på att det inte är språkets grad av specifikation och formalitet som avgör om en text bedöms ligga på den ena eller andra sidan av godkäntgränsen. Enligt resultatrapporter från nationella prov är också ett vanligt skäl till att en elevtext bedöms med betyget $\mathrm{F}$ att eleven inte har följt skrivinstruktionen eller inte har klarat av den källhantering som krävs (Broman \& Dalberg, 2017).

De undersökta kvantitativa textmåtten är alltså på olika sätt relevanta för bedömning av elevtexter i de två nationella proven. Måtten har dock ett tydligare samband med betyg för provet Np 1 än för Np 3, och de förefaller ha större betydelse för att skilja mellan mellanbetyg och höga betyg än mellan betyg längre ner på betygsskalan.

\section{Metoddiskussion}

De analyser som genomförts i denna undersökning har gett intressant men inte heltäckande kunskap om textmåtten i förhållande till benchmarktexter i de två proven. Ett par uppföljande forskningsfrågor har formulerats ovan, och den fortsatta forskningen bör också arbeta med fler språkmått, såväl som fler statistiska mått, exempelvis klusteranalyser, för att upptäcka mer svårfångade samband. Vidare behövs kvalitativa analyser som komplement till den automatiska analysen, exempelvis för att undersöka vilka egenskaper en text har, som i den kvantitativa analysen ligger långt ifrån "vanliga värden” för den betygsnivå texten representerar. Slutligen är språkteknologers kunskap nödvändig för att utveckla ett automatiskt verktyg. Vid Uppsala universitet pågår försök, ännu opublicerade, att finna vägar till en automatisk bedömning av elevtexter via språkteknologi och användning av neurala nätverk.

Min undersökning hade nått högre reliabilitet och validitet med ett större textunderlag i svenska som andraspråk, men jag har ändå sett det som meningsfullt att jämföra texter från de två svenskämnena. Om några år, när fler benchmarktexter finns att tillgå, kommer jag att kunna kontrollera resultaten från denna artikel med det utökade materialet.

\section{Konklusion}

Den viktigaste slutsatsen jag vill dra inför ett framtida arbete med automatisk bedömning av elevtexter är att den automatiska bedömningen måste designas efter ett specifikt skrivprov och de textnormer som är relevanta där. De undersökta måtten har visat sig vara i olika grad giltiga för bedömning av de två proven, de två svenskämnena och skillnaden mellan olika betygssteg. Vidare gäller olika nivåer av språkmåtten i olika prov, vilket bör ha betydelse för arbetet med ett bedömningsverktyg. En tredje slutsats är att en framtida automatisk bedömning måste utgöras av en mer mångfasetterad analys av elevtexten än den som genomförts här. I den kvalitativa analys som dagens 
bedömning utgår från ingår analys av en rad textegenskaper som inte fångas upp av de fyra textmåtten. Det gäller innehållets relevans för uppgiften, originalitet och nyansrikedom, källhantering (läsning, sovring, referat och citatteknik), textens struktur, textbindning, syntaktisk variation och språklig korrekthet. Medan vissa av textegenskaperna har analyserats automatiskt i engelska texter (jfr McNamara et al., 2014; Monaghan \& Bridgeman, 2005) måste nog andra bygga på kvalitativ bedömning av en mänsklig läsare. Med stöd av en automatisk analys borde dock bedömningens kvalitet kunna höjas.

\section{Om författaren}

Anne Palmér är universitetslektor och vetenskaplig ledare för de nationella proven i svenska och svenska som andraspråk. Hennes forskningsintressen omfattar bland annat muntlighet, bedömning och automatisk textanalys. Institutionsanknytning: Institutionen för nordiska språk, Uppsala universitet, Box 527, 75120 Uppsala.

E-post: anne.palmer@nordiska.uu.se

\section{Referenser}

Berman, R. \& Verhoeven, L. (2002). Cross-Linguistic Perspectives on the Development of Text-Production Abilities: Speech and Writing, Written Language and Literacy 5(1), 143. doi: https://doi.org/10.1075/wll.5.1.02ber

Berge, K. L. (2005). Studie 3. Skriveprøvenes pålitelighet. I K. L. Berge, L. S. Evensen, F Hertzberg \& W. Vagle (red.), Ungdomers skrivekompetanse, Bind 1, Norsksensuren som kvalitetsutvurdering (s. 101-113). Oslo: Universitetsforlaget.

Berge, K. L., Evensen, L., Hertzberg, F. \& Vagle, W. (2005). Ungdommers skrivekompetanse. Bind II, Norskeksamen som tekst. Oslo: Universitetsforlaget.

Borgström, E. (2014). Skrivbedömning. Uppgifter, texter och bedömningsanvisningar i svenskämnets nationella prov. Doktorsavhandling, Örebro universitet.

Broman, A. \& Dalberg, T. (2017). Resultatrapport kursprov 32017 - Nyckeln till framgång. Institutionen för nordiska språk, Uppsala universitet. Hämtat från http://www.natprov.nordiska.uu.se

af Geijerstam, Å. (2006). Att skriva i naturorienterande ämnen i skolan. Doktorsavhandling, Uppsala universitet.

Goodwin, S. (2016). A Many-Facet Rasch analysis comparing essay rater behavior on an academic English reading/writing test used for two purposes, Assessing Writing, 30, $21-$ 31. doi: https://doi.org/10.1016/j.asw.2016.07.004

Harsch, C. \& Martin, G. (2013). Comparing holistic and analytic scoring methods: issues of validity and reliability, Assessment in Education: Principles, Policy \& Practice, 20(3), 281-307. doi: https://www.tandfonline.com/doi/pdf/10.1080/0969594X.2012.742422

Hultman, T. G. (1994). Hur gick det med Ovix? I Språkbruk, grammatik och språkförändring. En festskrift till Ulf Teleman (s. 55-64). Lund: Lunds universitet. 
Hultman, T. G. \& Westman, M. (1977). Gymnasistsvenska. Lund: Liber Läromedel. Johansson, V. (2009). Developmental Aspects of Text Production in Writing and Speech. Diss. Lund: Department of Linguistics and Phonetics, Centre for Languages and Literature, Lund University. Hämtat från http://portal.research.lu.se/ws/files/5221582/1487260.pdf

Jönsson, A. \& Thornberg, P. (2014). Samsyn eller samstämmighet? En diskussion om sambedömning som redskap för likvärdig bedömning i skolan, Pedagogisk forskning i Sverige, 19(4-5), 386-402. Hämtat från: http://journals.lub.lu.se/index.php/pfs/article/view/13169/11758

Kann, W. (2013). Blir studenternas språk sämre? KTH Skolan för datavetenskap och kommunikation. doi:

http://kth.diva-portal.org/smash/get/diva2:1073626/FULLTEXT01.pdf

Larsson, K. (1984). Skrivförmåga. Studier av svenskt elevspråk. Doktorsavhandling, Uppsala universitet. Malmö: Liber förlag.

Ledin, P. \& Borgström, E. (2014). Bedömarvariation. Balansen mellan teknisk och hermeneutisk rationalitet vid bedömning av skrivprov, Språk \& Stil: Tidskrift för svensk språkforskning, 24 Ny följd, 133-165.

Magnusson, U. \& Johansson Kokkinakis, S. (2009). Quantitative measures on student texts. I P. Juvonen (red.), Språk och lärande. Rapport från ASLA:s höstsymposium, Stockholm, 78 november 2008 (s. 105-124). Göteborgs universitet.

Matre S. \& Solheim, R. (2014). Forventninger om skrivekompetanse. Perspektiver på skriving, skriveopplaering og vurdering i ”Normprojektet”, Viden om laesning 15, 76-88. Hämtat från: http://www.videnomlaesning.dk/media/1414/videnom_15_8.pdf

McNamara, D. S., Graesser, A. C., McCarthy, P. M. \& Cai, Z. (2014). Automated Evaluation of Text and Discourse with Coh-Metrix. New York: Cambridge University Press.

Megyesi, B., Näsman, J. \& Palmér, A. (2016). The Uppsala Corpus of Student Writings: Corpus Creation, Annotation, and Analysis, Proceedings of the Tenth International Conference on Language Resources and Evaluation (LREC 2016), 3192-3199. Paris: European Language Resources Association. Hämtat från:

http://www.lrec-conf.org/proceedings//rec2016/pdf/121_Paper.pdf

Melin, L. \& Lange, S. (2006). Att analysera text. Stilanalys med exempel. Lund: Studentlitteratur.

Monaghan, W. \& Bridgeman, B. (2005). E-rater as a Quality Control on Human Scores. ETS Research and development. Princeton. doi: https://www.ets.org/Media/Research/pdf/RD_Connections2.pdf.

Nordenfors, M. (2011). Skriftspråksutveckling under högstadiet. Doktorsavhandling, Göteborgs universitet.

Nyström, C. (2000). Gymnasisters skrivande. En studie av genre, textstruktur och sammanhang. Doktorsavhandling, Uppsala universitet.

Näsman, J., Megyesi, B. \& Palmér, A. (2017). SWEGRAM - A Web-Based Tool for Automatic Annotation and Analysis of Swedish Texts, Nordic Conference on Computational Linguistics (NoDaLiDa), 132-141. Hämtat från:

https://uu.diva-portal.org/smash/get/diva2:1169892/FULLTEXT01.pdf

Skar, G. (2013). Skrivbedömning och validitet. Fallstudier av skrivbedömning i svenskundervisning på gymnasiet. Doktorsavhandling, Stockholms universitet. Hämtat från https://www.diva-portal.org/smash/get/diva2:623658/FULLTEXT01.pdf

Skolverket 2017a. Kursprov vt 2017. Svenska och svenska som andraspråk 1. Lärarinformation. Vad jag vill och vad jag väljer. Stockholm: Skolverket. 
Skolverket 2017b. Kursprov vt 2017. Svenska och svenska som andraspråk 1.

Bedömningsanvisningar delprov B och C. Vad jag vill och vad jag väljer. Stockholm: Skolverket.

Skolverket (2011) Läroplan, examensmål och gymnasiegemensamma ämnen för gymnasieskola 2011( Lgy11). Stockholm: Skolverket.

Utbildningsdepartementet (1994). Läroplan för de frivilliga skolformerna (Lpf94). Stockholm: Utbildningsdepartementet.

Vagle, W. (2005). Tekstlengde + ordlengdesnitt = kvalitet? I K. L. Berge, L. Evensen, F. Hertzberg, F. \& W. Vagle (red.), Ungdommers skrivekompetanse, Bind II, (s. 303-387). Oslo: Universitetsforlaget.

Wang, Z. \& Davier, A. A. (2014). Monitoring of Scoring Using the E-rater Automated Scoring System and Human Raters on a Writing Test. ETS Research Report 14-04.. Princeton: ETS Educational Testing Service. doi: https://onlinelibrary.wiley.com/doi/epdf/10.1002/ets2.12005

Östling, R., Smolenzov, A., Tyrefors, B. \& Hinnerich, B. (2013). Automated Essay Scoring for Swedish, Proceedings of the Eighth Workshop on Innovative Use of NLP for Building Educational Applications, 42-47. Association for Computational Linguistics. Hämtat från: http://www.aclweb.org/anthology/W13-1705

Östlund-Stjärnegårdh, E. (2002). Godkänd i svenska? Bedömning och analys av gymnasieelevers texter. Doktorsavhandling, Uppsala universitet. 